\title{
The Impact of Different Insulin-Related Measures on the Risk of Prediabetes Among the Chinese Han Population
}

\author{
Huibiao Quan · Tuanyu Fang • Leweihua Lin · Lu Lin • \\ Qianying Ou · Huachuan Zhang · Kaining Chen · Zhiguang Zhou
}

Received: April 29, 2021 / Accepted: June 15, 2021 / Published online: July 8, 2021

(C) The Author(s) 2021

\section{ABSTRACT}

Introduction: Diabetes mellitus (DM) has a serious impact on people's lives in the world. Interventions that affect risk factors for prediabetes can prevent and reduce diabetes occurrence. Proinsulin (PI), true insulin (TI), and proinsulin to insulin ratio (PI/TI) are risk factors for diabetes. The roles of these indicators in prediabetes are unclear. This study aimed to evaluate the impact of PI, TI, PI/TI, 2-h proinsulin (2hPI), 2-h true insulin (2hTI), and $2 \mathrm{hPI} /$ $2 \mathrm{hTI}$ on the risk of prediabetes among the Chinese Han population.

Methods: This cross-sectional study recruited 1688 subjects including 718 prediabetes cases and 970 non-prediabetes controls from Hainan Affiliated Hospital of Hainan Medical

H. Quan · Z. Zhou ( $₫)$

Department of Metabolism and Endocrinology, The Second Xiangya Hospital, Central South University, No. 139, Renmin Middle Road, Furong District, Changsha 410011, Hunan Province, China e-mail: zhouzhiguang@csu.edu.cn

H. Quan · T. Fang · L. Lin · L. Lin · Q. Ou . H. Zhang · K. Chen

Department of Endocrinology, Hainan General Hospital, Hainan Affiliated Hospital of Hainan Medical University, No.19, Xiuhua Road, Haikou 570311, Hainan, China
University. The cases involved 292 men and 426 women. The controls involved 324 men and 646 women. The mean age was $53.62 \pm 12.43$ years in the prediabetes group and $44.24 \pm 12.87$ years in the non-prediabetes group.

Results: Our results showed that PI, TI, PI/TI, $2 \mathrm{hPI}, 2 \mathrm{hTI}$, and $2 \mathrm{hPI} / 2 \mathrm{hTI}$ were significantly correlated with prediabetes (all $p<0.05$ ). Logistic regression analysis revealed that PI (OR 1.022, 95\% CI 1.014-1.031, $p=0.00011$ ), TI $\quad($ OR $1.005, \quad 95 \% \quad$ CI 1.003-1.007, $p=0.00012), \quad$ PI $/ \mathrm{TI} \quad(\mathrm{OR} 1.517, \quad 95 \%$ CI 1.080-2.131, $p=0.016$ ), and 2hTI (OR 1.000, 95\% CI 1.000-1.001, $p=0.002$ ) were significantly associated with an increased risk of prediabetes. Receiver operating characteristic curve (ROC) analysis indicated that the area under the ROC curve (AUC) of the combination (PI + $\mathrm{TI}+\mathrm{PI} / \mathrm{TI}+2 \mathrm{hPI}+2 \mathrm{hTI}+2 \mathrm{hPI} / 2 \mathrm{hTI})$ in diagnosing prediabetes was 0.627 , which was larger than the diagnostic value of HOMA-IR (AUC 0.614) and HOMA- $\beta$ (AUC 0.387).

Conclusions: Our study showed that PI, TI, PI/ TI, and 2hTI could significantly enhance the risk of prediabetes in the Chinese Han population, which suggested that PI, TI, PI/TI, and 2hTI might be available risk factors for prediabetes.

Keywords: Prediabetes; Insulin; Proinsulin; Risk 


\section{Key Summary Points}

PI, TI, PI/TI, 2hPI, 2hTI, and 2hPI/2hTI were significantly correlated with prediabetes.

PI, TI, PI/TI, and 2hTI could significantly enhance the risk of prediabetes in the Chinese Han population.

The combination of PI, TI, PI/TI, 2hPI, $2 \mathrm{hTI}, 2 \mathrm{hPI} / 2 \mathrm{hTI}$ might be a promising biomarker for diagnosing prediabetes among the Chinese Han population.

\section{DIGITAL FEATURES}

This article is published with digital features, including a summary slide to facilitate understanding of the article. To view digital features for this article go to https://doi.org/10.6084/ m9.figshare. 14785398

\section{INTRODUCTION}

Prediabetes, also known as impaired glucose regulation (IGR), is the abnormal glucose metabolism between the normal and diabetic state, including impaired fasting glucose (IFG), impaired glucose tolerance (IGT), or both [1]. Previous studies reported that the pathophysiology of prediabetes was associated with a decline in $\beta$ cell function, decreased insulin secretion, and increased insulin resistance $[2,3]$. The prevalence of elevated blood glucose levels among populations in both developed and developing countries is rising rapidly, and the number of individuals with prediabetes is expected to increase by about one-third by the middle of the century $[4,5]$. According to epidemiological surveys, the prevalence of prediabetes in the same population is often higher than that of diabetes, and people with prediabetes risk factors are significantly more likely to have type 2 diabetes mellitus (T2DM) and its associated complications (chronic kidney disease, diabetic retinopathy, cognitive dysfunction, and macrovascular disease) compared with the ordinary population [6-9]. About $5-10 \%$ of IGT gradually changes to T2DM every year [10]. An effective prevention strategy for prediabetes is important to delay or even prevent the development of overt diabetes [11, 12]. In order to control and reduce the occurrence of diabetes, interventions affecting prediabetes risk factors should be strengthened.

Human proinsulin (PI) is the precursor of true insulin (TI) and consists of c and TI peptide. PI is synthesized and secreted by pancreatic $\beta$ cells and metabolized primarily in the kidneys. Under physiological conditions, only a small amount of PI is released into the blood, whereas under pathological conditions, pancreatic cells can release PI leading to increasing PI in the blood. PI, TI, and proinsulin to insulin ratio (PI/TI) are the important markers for impaired glucose metabolism. Pradhan's study indicated that PI, TI, and PI/TI were strongly associated with the development of T2DM, and they suggested that proinsulin levels might be a marker for more rapid progression to T2DM [13]. TI is synthesized in the $\beta$ cells from PI, and PI accounts for $10-20 \%$ of fasting insulin in normoglycemia [14]. TI is the main treatment for type 1 diabetes (T1DM), and is also central to the management of T2DM. It is reported that fasting PI levels are associated with insulin resistance in T2DM, but not with T1DM [15-17]. Besides, the PI/TI is the way to measure impaired insulin secretory mechanism within pancreatic $\beta$ cells in clinical practice. The fasting $\mathrm{PI} / \mathrm{TI}$ ratio is regarded as a marker of acute insulin response, and the increased PI/TI in plasma represents a higher risk of diabetes [18].

Taken together, we suggest that investigating the impacts of the risk factors (PI, TI, and PI/TI) for diabetes on prediabetes risk may help to prevent and reduce the occurrence of diabetes. However there is not any survey focusing on the association of these indicators with prediabetes risk. Thus, this cross-sectional study was conducted to investigate the effect of PI, TI, PI/TI, $2 \mathrm{hPI}, 2 \mathrm{hTI}$, and $2 \mathrm{hPI} / 2 \mathrm{hTI}$ on the risk of prediabetes in the Chinese Han population. We further evaluated the diagnostic value of PI, TI, PI/ 
TI, 2hPI, 2hTI, 2hPI/2hTI, and their combinations in prediabetes diagnosis. The present study should give some available information for the prevention and management of diabetes in the Chinese population or others.

\section{METHODS}

\section{Study Population}

In the present study, a total of 1688 residents aged over 18 years old were randomly enrolled from Hainan Affiliated Hospital of Hainan Medical University to undergo a 75-g oral glucose tolerance test (OGTT). Each participant was informed of the purpose of sample collection and we obtained written informed consent from them before starting the study. For this study, the required smallest sample size was 1670 based on the following formula: $n=Z^{2} \times p \times q$ / $e^{2}=1.96^{2} \times 0.224 \times(1-0.224) / 0.02^{2}=1670$, $n$ = sample size, $Z=1.96$ for confidence interval of $95 \%, p=$ prevalence of prediabetes among Hainan Han adults, 0.226, $q=1-p, e=$ margin of error, $2 \%$. Prediabetes was defined as any participant who did not have diabetes but who had a hemoglobin A1C (HbA1c) concentration of $5.7-6.4 \%$, or fasting plasma glucose (FPG) concentration of $5.6-7.0 \mathrm{mmol} / \mathrm{L}$, or 2-h plasma glucose (2hPG) concentration of 7.8-$11.1 \mathrm{mmol} / \mathrm{L}$ according to the American Diabetes Association (ADA) 2018 guidelines [19]. Non-prediabetes was defined as the proportion of individuals with an HbA1c concentration of less than $5.7 \%$, or FPG concentration of less than $5.6 \mathrm{mmol} / \mathrm{L}$, or $2 \mathrm{hPG}$ concentration of less than $7.8 \mathrm{mmol} / \mathrm{L}$. All subjects must meet the following exclusion criteria: (1) HbA1c concentration was $6.5 \%$ and over; (2) using oral hypoglycemic drugs; (3) severe liver and kidney diseases; (4) metabolic osteopathy; (5) tumors; (6) pregnancy. Our study was approved by the Ethics Committee of Hainan Affiliated Hospital of Hainan Medical University (Med-Eth-Re [2019] 18) and all experiments were carried out in accordance with the standard protocol of Helsinki's Declaration of 1964, and its later amendments.

\section{Anthropometric Measurements}

Characteristics of each participant were obtained according to a standardized questionnaire and medical records, including age, sex, body mass index (BMI), blood pressure, family history of diabetes, and smoking status. The blood pressure, height, body weight, and waist circumference (WC) of all subjects were measured on an empty stomach in the morning. BMI was assessed as weight (kilograms) divided by the square of the height (meters). WC was measured twice at $1.0 \mathrm{~cm}$ horizontally by trained investigators under standardized conditions. We used an automatic biochemical analyzer (Hitachi 7060, Tokyo) to analyze FPG (Blood Sugar Content Assay Kit, Colorimetric Method, Sangon Biotech Co., Ltd. Shanghai), 2hPG (Blood Sugar Content Assay Kit, Colorimetric Method, Sangon Biotech Co., Ltd. Shanghai), triglyceride (TG) (Triglyceride Content Assay Kit, Colorimetric Method, Sangon Biotech Co., Ltd. Shanghai), total cholesterol (TC) (Total Cholestenone Content Assay Kit, Colorimetric method), low-density lipoprotein cholesterol (LDL-C) (Human LDL ELISA Kit, Sangon Biotech Co., Ltd. Shanghai), and highdensity lipoprotein cholesterol (HDL-C) (Human HDL ELISA Kit, Sangon Biotech Co., Ltd. Shanghai), from overnight fasting blood samples. TI levels were measured by a chemiluminescent enzyme immunoassay (Insulin Elecsys; Roche Diagnostics, Alameda, CA, USA). PI was analyzed by means of a specific ELISA method (TecoMedical, Sissach, Switzerland). The concentration of $25(\mathrm{OH})$-vitamin $\mathrm{D}_{3}$ (VD3) in the serum was tested by using a non-radioactive enzyme immunoassay kit (EIA kit, ImmunoDiagnostic Systems Ltd. Boldon) with a calibration range from 3 to $70 \mathrm{ng} / \mathrm{mL}$. Whole blood HbA1c was measured in packed red blood cell samples by a turbidimetric immunoinhibition method (Tina-quant; Roche Diagnostics, Indianapolis, Indiana). Insulin resistance (IR) and pancreatic $\beta$ cell function were estimated by a homeostasis model assessment, using the following formula [20]: HOMA-IR = (fasting insulin $[\mathrm{mIU} / \mathrm{L}] \times$ FPG $[\mathrm{mmol} / \mathrm{L}]) / 22.5$; HOMA- $\beta$ : $[20 \times$ fasting insulin $(\mu \mathrm{U} / \mathrm{mL})] /[$ fasting glucose $(\mathrm{mmol} / \mathrm{L})-3.5]$. 
Table 1 Characteristics of prediabetes and non-prediabetes

\begin{tabular}{|c|c|c|c|}
\hline Variants & Controls $(N=970)$ & Cases $(N=718)$ & $p$ \\
\hline Age & $44.24 \pm 12.87$ & $53.62 \pm 12.43$ & $<0.001^{a}$ \\
\hline Sex & & & $0.003^{\mathrm{b}}$ \\
\hline Men & 324 & 292 & \\
\hline Women & 646 & 426 & \\
\hline BMI $\left(\mathrm{kg} / \mathrm{m}^{2}\right)$ & $23.19 \pm 3.42$ & $24.53 \pm 3.78$ & $<0.001^{\mathrm{a}}$ \\
\hline WC $(\mathrm{cm})$ & $79.25 \pm 9.77$ & $83.94 \pm 11.29$ & $<0.001^{\mathrm{a}}$ \\
\hline FPG $(\mathrm{mg} / \mathrm{dL})$ & $5.05 \pm 0.55$ & $6.14 \pm 2.05$ & $<\mathbf{0 . 0 0 1}^{\mathrm{a}}$ \\
\hline $2 \mathrm{hPG}(\mathrm{mmol} / \mathrm{L})$ & $6.66 \pm 1.74$ & $9.41 \pm 4.33$ & $<0.001^{\mathrm{a}}$ \\
\hline $\mathrm{TG}(\mathrm{mmol} / \mathrm{L})$ & $1.64 \pm 1.18$ & $2.3 \pm 2.49$ & $<0.001^{\mathrm{a}}$ \\
\hline $\mathrm{TC}(\mathrm{mmol} / \mathrm{L})$ & $5.25 \pm 1.04$ & $5.65 \pm 1.14$ & $<0.001^{\mathrm{a}}$ \\
\hline LDL-C (mmol/L) & $2.83 \pm 0.8$ & $3.11 \pm 0.86$ & $<0.001^{\mathrm{a}}$ \\
\hline HDL-C (mmol/L) & $1.54 \pm 0.4$ & $1.46 \pm 0.44$ & $<0.001^{\mathrm{a}}$ \\
\hline $\mathrm{VD} 3(\mathrm{ng} / \mathrm{mL})$ & $37.2 \pm 10.93$ & $38.31 \pm 10.55$ & $0.036^{\mathrm{a}}$ \\
\hline $\mathrm{PI}(\mathrm{mmol} / \mathrm{L})$ & $12.43 \pm 9.29$ & $16.01 \pm 17.07$ & $<0.001^{\mathrm{a}}$ \\
\hline $2 \mathrm{hPI}(\mathrm{mmol} / \mathrm{L})$ & $63.91 \pm 53.48$ & $59.78 \pm 53.33$ & $0.120^{\mathrm{a}}$ \\
\hline $\mathrm{TI}(\mathrm{mmol} / \mathrm{L})$ & $61.81 \pm 44.47$ & $73.31 \pm 57.75$ & $<0.001^{\mathrm{a}}$ \\
\hline $2 \mathrm{hTI}(\mathrm{mmol} / \mathrm{L})$ & $467.19 \pm 405.92$ & $535.68 \pm 490.51$ & $0.002^{\mathrm{a}}$ \\
\hline $\mathrm{PI} / \mathrm{TI}$ & $0.24 \pm 0.19$ & $0.25 \pm 0.29$ & $0.227^{a}$ \\
\hline $2 \mathrm{hPI} / 2 \mathrm{hTI}$ & $0.19 \pm 0.21$ & $0.21 \pm 1.34$ & $0.619^{\mathrm{a}}$ \\
\hline HbAlc (\%) & $5.24 \pm 0.33$ & $6.39 \pm 1.18$ & $<0.0001^{\mathrm{a}}$ \\
\hline HOMA-IR & $1.41 \pm 1.23$ & $2.03 \pm 1.95$ & $<0.0001^{\mathrm{a}}$ \\
\hline HOMA- $\beta$ (\%) & $8.52 \pm 6.02$ & $7.04 \pm 6.31$ & $<0.0001^{\mathrm{a}}$ \\
\hline Hypertension & $120(12.4 \%)$ & $179(25.0 \%)$ & \\
\hline Normotension & $849(87.6 \%)$ & $537(75.0 \%)$ & \\
\hline \multicolumn{4}{|l|}{ Smoking status } \\
\hline Never & $784(81.5 \%)$ & $548(77.2 \%)$ & \\
\hline Sometimes & $43(4.5 \%)$ & $34(4.8 \%)$ & \\
\hline Often & $135(14.0 \%)$ & $128(18.0 \%)$ & \\
\hline \multicolumn{4}{|c|}{ Family history of diabetes } \\
\hline Yes & $134(13.9 \%)$ & $118(16.7 \%)$ & \\
\hline
\end{tabular}


Table 1 continued

\begin{tabular}{llll}
\hline Variants & Controls $(\boldsymbol{N}=\mathbf{9 7 0})$ & Cases $(\boldsymbol{N}=\mathbf{7 1 8})$ & $\boldsymbol{p}$ \\
\hline No & $831(86.1 \%)$ & $590(83.3 \%)$ & \\
\hline
\end{tabular}

Numbers in bold are statistically significant $(p<0.05)$

$B M I$ body mass index, $W C$ waist circumference, $S P$ systolic pressure, DP diastolic pressure, FPG fasting plasma glucose, $H b A 1 c$ glycosylated hemoglobin, $T C$ total cholesterol, $T G$ triglyceride, $H D L-C$ high-density lipoprotein cholesterol, $L D L-C$ low-density lipoprotein cholesterol, $V D 325(\mathrm{OH})$-vitamin $\mathrm{D}_{3}, P I$ proinsulin, $T I$ true insulin, 2 hPI 2-h proinsulin, 2 hTI 2-h true insulin, $I R$ insulin resistance

a Calculated by Student's $t$ test

b Calculated by $X^{2}$ test

\section{Statistical Analysis}

Statistical analysis was conducted using SPSS 21.0 software (SPSS, Chicago, IL, USA). Student's $t$ test was used to compare the differences in age and characteristics between the prediabetes and non-prediabetes group. The difference of sex between the two groups was analyzed by the chi-square test. Spearman's correlation analysis was performed to evaluate the interrelationship between different indicators. The impacts of PI, TI, PI/TI, 2hPI, 2hTI, and $2 \mathrm{hPI} / 2 \mathrm{hTI}$ on the risk of prediabetes were assessed by logistic regression analysis. Receiver operating characteristic curve (ROC) was carried out to evaluate the diagnostic performance of PI, TI, PI/TI, 2hPI, 2hTI, and $2 \mathrm{hPI} / 2 \mathrm{hTI}$, and the cutoff points also were computed in diagnosing prediabetes. The area under the ROC curve (AUC) was compared to determine the diagnostic value of PI, TI, PI/TI, 2hPI, 2hTI, 2hPI/ $2 \mathrm{hTI}$, and their combination for prediabetes. All tests were two-sided and $p<0.05$ was considered as statistically significant.

\section{RESULTS}

\section{Characteristics of Participants}

The characteristics of participants are presented in Table 1. Our study involved 718 prediabetes and 970 non-prediabetes cases. The mean age was $53.62 \pm 12.43$ years in the prediabetes group and $44.24 \pm 12.87$ years in the non-prediabetes group. There were significant differences in age, sex, BMI, WC, FPG, 2hPG, TG, TC,
LDL-C, HDL-C, PI, TI, 2hTI, VD3, HbA1c, HOMA-IR, and HOMA- $\beta$ between the two groups (all $p<0.05$ ). No significant difference was observed in 2hPI, PI/TI, and $2 \mathrm{hPI} / 2 \mathrm{hTI}$ between the two groups (all $p>0.05$ ).

\section{Association Analyses Among Indicators in Prediabetes}

A Spearman's association analysis was carried out to detect the interrelationships of PI, TI, PI/ TI, 2hPI, 2hTI, 2hPI/2hTI, HOMA-IR, and HOMA- $\beta$ with other indicators in prediabetes. As shown in Table 2, PI was positively correlated with FPG $(r=0.263)$, 2hPG $(r=0.171)$, HbA1c $(r=0.090)$, LDL-C $(r=0.048)$, TG $(r=0.197)$, TC $(r=0.068)$, BMI $(r=0.275)$, WC $(r=0.271)$, and VD3 $(r=0.058)$, and negatively related to HDL-C $(r=-0.118)$. TI was positively associated with FPG $(r=0.240)$, 2hPG $(r=0.199)$, HbA1c $\quad(r=0.108), \quad$ LDL-C $\quad(r=0.116), \quad$ TG $(r=0.235)$, TC $(r=0.085), \mathrm{BMI}(r=0.428)$, and WC $(r=0.375)$, and negatively related to HDLC $(r=-0.240)$ and VD3 $(r=-0.108)$. PI/TI was positively correlated with FPG $(r=0.064)$, HDL-C $(r=0.056)$, and VD3 $(r=0.170)$, and negatively associated with LDL-C $(r=-0.054)$, and BMI $(r=-0.066)$. 2hPI was positively related to FPG $(r=0.154)$, 2hPG $(r=0.196)$, LDL-C $\quad(r=0.060), \quad$ TG $\quad(r=0.082), \quad$ TC $(r=0.077)$, BMI $(r=0.189)$, WC $(r=0.181)$, and VD3 $(r=0.082)$, and negatively related to HbA1c $(r=-0.078)$ and HDL-C $(r=-0.070)$. 2hTI positively related to FPG $(r=0.120), 2 \mathrm{hPG}$ $(r=0.439)$, LDL-C $(r=0.129)$, TG $(r=0.162)$, TC $(r=0.078), \quad$ BMI $(r=0.285), \quad$ and WC 
Table 2 Association analysis among indicators in prediabetes

\begin{tabular}{lccccccccccc}
\hline & FPG & 2hPG & HbA1c & HDL-C & LDL-C & TG & TC & BMI & WC & VD3 \\
\hline PI (mmol/L) & $0.263^{* *}$ & $0.171^{* *}$ & $0.090^{* *}$ & $-0.118^{* *}$ & $0.048^{*}$ & $0.197^{* *}$ & $0.068^{* *}$ & $0.275^{* *}$ & $0.271^{* *}$ & $0.058^{*}$ \\
TI $(\mathrm{mmol} / \mathrm{L})$ & $0.240^{* *}$ & $0.199^{* *}$ & $0.108^{* *}$ & $-0.240^{* *}$ & $0.116^{* *}$ & $0.235^{* *}$ & $0.085^{* *}$ & $0.428^{* *}$ & $0.375^{* *}$ & $-0.108^{* *}$ \\
PI/TI & $0.064^{* *}$ & 0.021 & -0.007 & $0.056^{*}$ & $-0.054^{*}$ & 0.029 & -0.008 & $-0.066^{* *}$ & -0.031 & $0.170^{* *}$ \\
2hPI (mmol/L) & $0.154^{* *}$ & $0.196^{* *}$ & $-0.078^{* *}$ & $-0.070^{* *}$ & $0.060^{*}$ & $0.082^{* *}$ & $0.077^{* *}$ & $0.189^{* *}$ & $0.181^{* *}$ & $0.082^{* *}$ \\
2hTI (mmol/L) & $0.120^{* *}$ & $0.439^{* *}$ & 0.021 & $-0.210^{* *}$ & $0.129^{* *}$ & $0.162^{* *}$ & $0.078^{* *}$ & $0.285^{* *}$ & $0.237^{* *}$ & $-0.061^{*}$ \\
2hPI/2hTI & 0.033 & $-0.228^{* *}$ & $-0.119^{* *}$ & $0.115^{* *}$ & $-0.063^{*}$ & $-0.083^{* *}$ & 0.003 & $-0.077^{* *}$ & -0.041 & $0.139^{* *}$ \\
HOMA-IR & $0.451^{* *}$ & $0.319^{* *}$ & $0.234^{* *}$ & $-0.225^{* *}$ & $0.140^{* *}$ & $0.266^{* *}$ & $0.128^{* *}$ & $0.433^{* *}$ & $0.393^{* *}$ & $-0.060^{*}$ \\
HOMA- $\beta$ & $-0.392^{* *}$ & $-0.152^{* *}$ & $-0.227^{* *}$ & $-0.162^{* *}$ & 0.002 & $0.071^{* *}$ & $-0.044^{* *}$ & $0.235^{* *}$ & $0.179^{* *}$ & $-0.199^{* *}$ \\
\hline
\end{tabular}

$F P G$ fasting plasma glucose, $2 h P G$ 2-h postprandial blood glucose, $H b A l c$ glycosylated hemoglobin, $H D L$ - $C$ high-density lipoprotein cholesterol, $L D L-C$ low-density lipoprotein cholesterol, $T C$ total cholesterol, $T G$ triglyceride, $P I$ proinsulin, $T I$ true insulin

${ }^{* *} p<0.01 ;{ }^{*} p<0.05$

Table 3 Risk factors for prediabetes by binary logistic regression analysis

\begin{tabular}{lllllll}
\hline Variables & $\boldsymbol{B}$ & $\boldsymbol{S E}$ & Wald & $\boldsymbol{p}$ & OR & 95\% CI \\
\hline $\mathrm{PI}(\mathrm{mmol} / \mathrm{L})$ & 0.022 & 0.004 & 27.061 & $\mathbf{0 . 0 0 0 1 1}$ & 1.022 & $1.014-1.031$ \\
$\mathrm{TI}(\mathrm{mmol} / \mathrm{L})$ & 0.005 & 0.001 & 19.301 & $\mathbf{0 . 0 0 0 1 2}$ & 1.005 & $1.003-1.007$ \\
$\mathrm{PI} / \mathrm{TI}$ & 0.417 & 0.173 & 5.782 & $\mathbf{0 . 0 1 6}$ & 1.517 & $1.080-2.131$ \\
$2 \mathrm{hPI}(\mathrm{mmol} / \mathrm{L})$ & -0.001 & 0.001 & 2.414 & 0.120 & 0.999 & $0.997-1.000$ \\
$2 \mathrm{hTI}(\mathrm{mmol} / \mathrm{L})$ & 0.0001 & 0.0001 & 9.277 & $\mathbf{0 . 0 0 2}$ & 1.000 & $1.000-1.001$ \\
$2 \mathrm{hPI} / 2 \mathrm{hTI}$ & 0.060 & 0.075 & 0.633 & 0.426 & 1.061 & $0.917-1.229$ \\
HOMA-IR & 0.323 & 0.045 & 52.312 & 0.0001 & 1.382 & $1.266-1.509$ \\
HOMA- $\beta$ & -0.046 & 0.010 & 22.650 & 0.0001 & 0.955 & $0.937-0.973$ \\
\hline
\end{tabular}

$p$ values were calculated by logistic regression analysis

Numbers in bold are statistically significant $(p<0.05)$

$O R$ odds ratio, $C I$ confidence interval

$(r=0.237)$, negatively associated with HDL-C $(r=-0.210)$ and VD3 $(r=-0.061)$. 2hPI/ 2hTI was positively related to HDL-C $(r=0.115)$ and VD3 $(r=0.139)$, and negatively associated with 2hPG $(r=-0.228)$, HbA1c $(r=-0.119)$, LDL-C $(r=-0.063)$, TG $(r=-0.083)$, and BMI $(r=-0.077)$. Besides, HOMA-IR was positively correlated with FPG $(r=0.451)$, 2hPG $(r=0.319), \quad$ HbA1c $\quad(r=0.234), \quad$ LDL-C $(r=0.140)$, TG $(r=0.266)$, TC $(r=0.128)$, BMI $(r=0.433)$, and WC $(r=0.393)$, and negatively related to HDL-C $(r=-0.225)$ and VD3 $(r=-0.060)$. HOMA- $\beta$ was positively associated with TG $(r=0.071)$, BMI $(r=0.235)$, and WC $(r=0.179)$, and negatively related to FPG $(r=-0.392), 2$ hPG $(r=-0.152)$, HbA1c $(r=-0.227), \quad$ HDL-C $\quad(r=-0.162), \quad$ TC $(r=-0.044)$, and VD3 $(r=-0.199)$.

\section{Impacts of Indicators on Risk of Prediabetes}

We further detected the association of PI, TI, PI/ TI, 2hPI, 2hTI, 2hPI/2hTI, HOMA-IR, and HOMA- $\beta$ with prediabetes risk by regression models. As shown in Table 3, we observed that 
PI (OR 1.022, 95\% CI 1.014-1.031, $p=0.00011)$, TI (OR 1.005, 95\% CI 1.003-1.007, $p=0.00012), \quad$ PI/TI $\quad$ (OR 1.517, $95 \%$ CI 1.080-2.131, $p=0.016$ ), 2hTI (OR 1.000, 95\% CI 1.000-1.001, $p=0.002$ ), and HOMA-IR (OR 1.382, 95\% CI 1.266-1.509, $p=0.0001$ ) were significantly associated with an increased risk of prediabetes, while HOMA- $\beta$ showed a protective role (OR 0.955 , 95\% CI 0.937-0.973, $p=0.0001)$.

\section{Diagnostic Value of Indicators for Prediabetes}

Then, we performed ROC curve analysis to analyze the prognostic accuracy of the indicators for diagnosing prediabetes (Figs. 1, 2, 3, 4, $5,6,7,8,9$; Table 4). The results revealed that the AUC of the combination (PI $+\mathrm{TI}+\mathrm{PI} /$ $\mathrm{TI}+2 \mathrm{hPI}+2 \mathrm{hTI}+2 \mathrm{hPI} / 2 \mathrm{hTI})$ in diagnosing prediabetes was 0.627 , with a specificity and sensitivity of $55.1 \%$ and $63.4 \%$, respectively. The AUC of the combination was larger than the diagnostic value of HOMA-IR (AUC 0.614) and HOMA- $\beta$ (AUC 0.387) diagnoses.

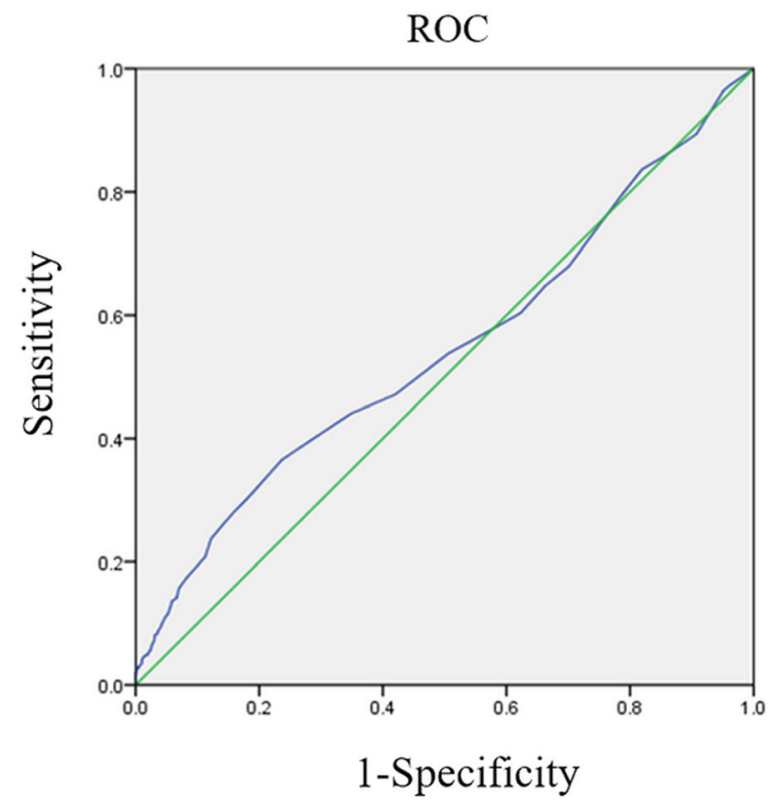

Fig. 1 ROC analysis of PI for diagnosing prediabetes

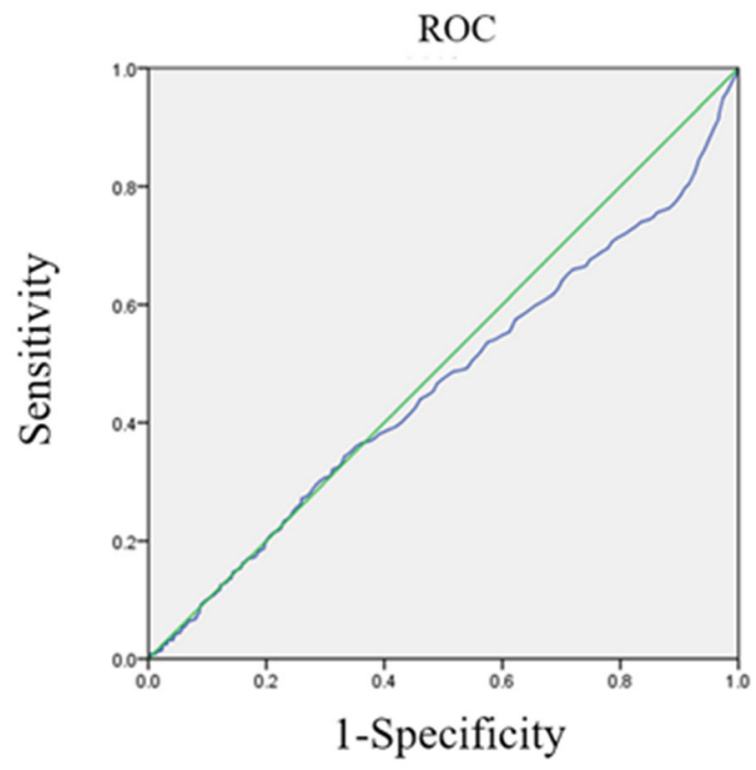

Fig. 2 ROC analysis of TI for diagnosing prediabetes

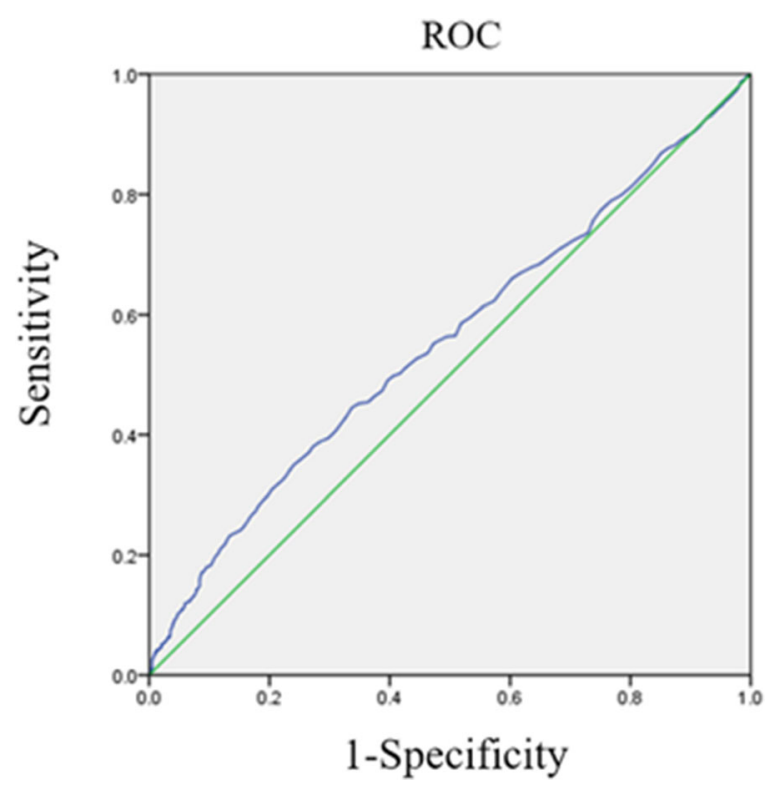

Fig. 3 ROC analysis of PI/TI for diagnosing prediabetes

\section{DISCUSSION}

In the present study, we recruited 718 prediabetes and 970 non-prediabetes cases to detect 


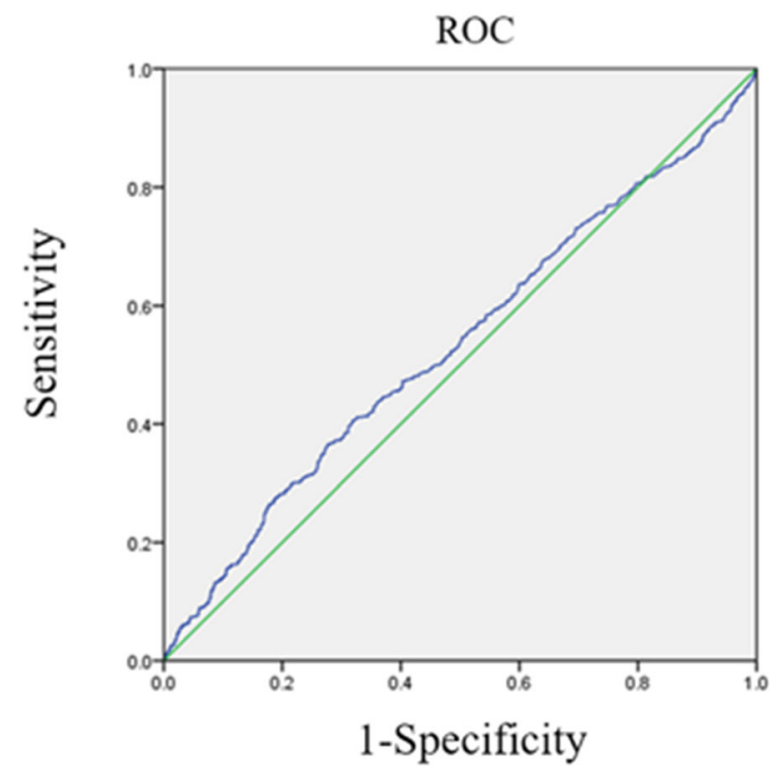

Fig. 4 ROC analysis of 2hPI for diagnosing prediabetes

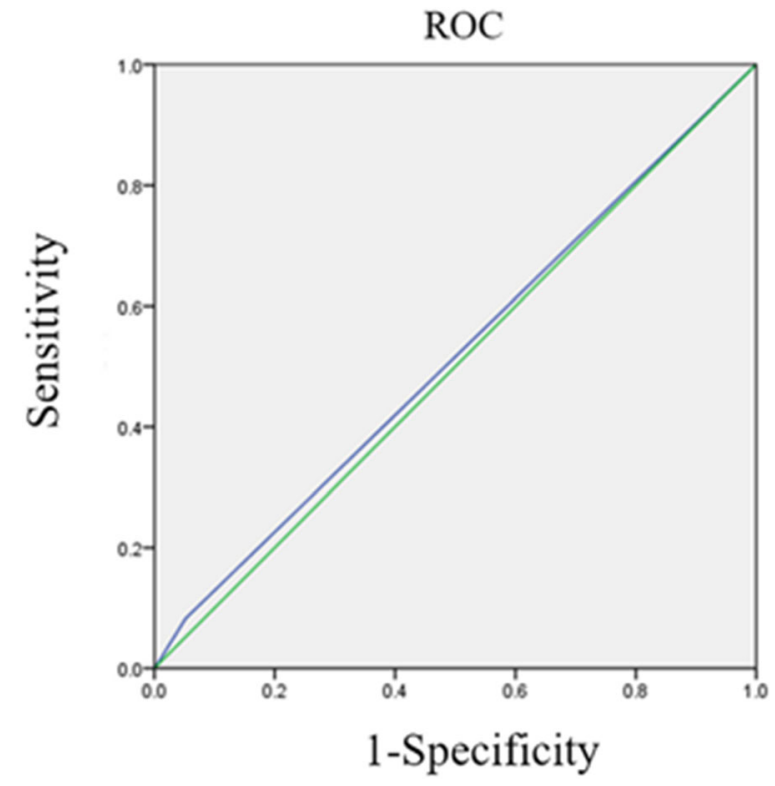

Fig. 5 ROC analysis of $2 \mathrm{hTI}$ for diagnosing prediabetes

the impact of PI, TI, PI/TI, 2hPI, 2hTI, and 2hPI/ $2 \mathrm{hTI}$ on prediabetes risk. Our study showed that PI, TI, PI/TI, 2hPI, 2hTI, and 2hPI/2hTI were significantly correlated with prediabetes.

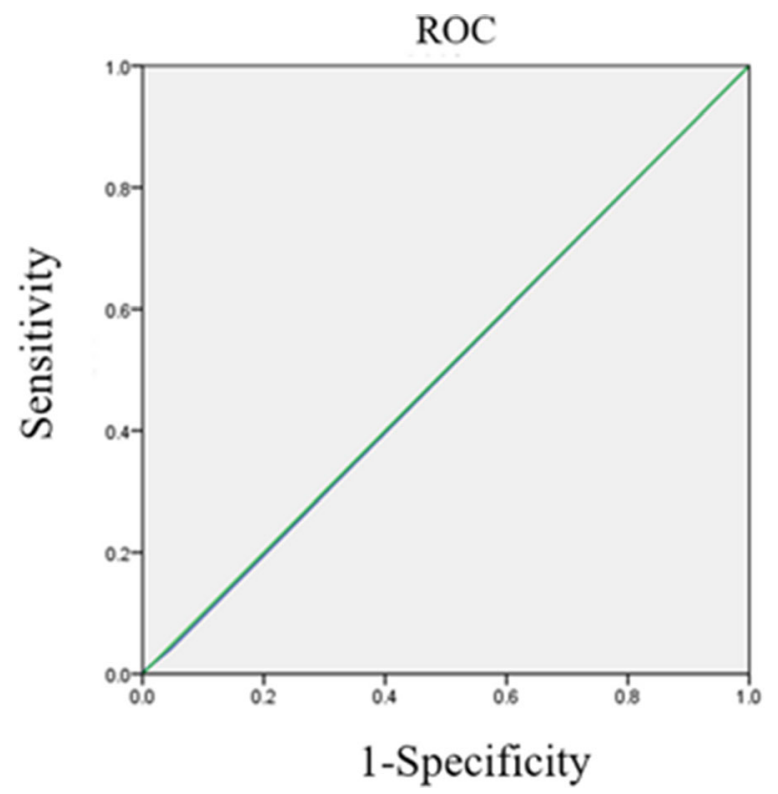

Fig. 6 ROC analysis of 2hPI/2hTI for diagnosing prediabetes

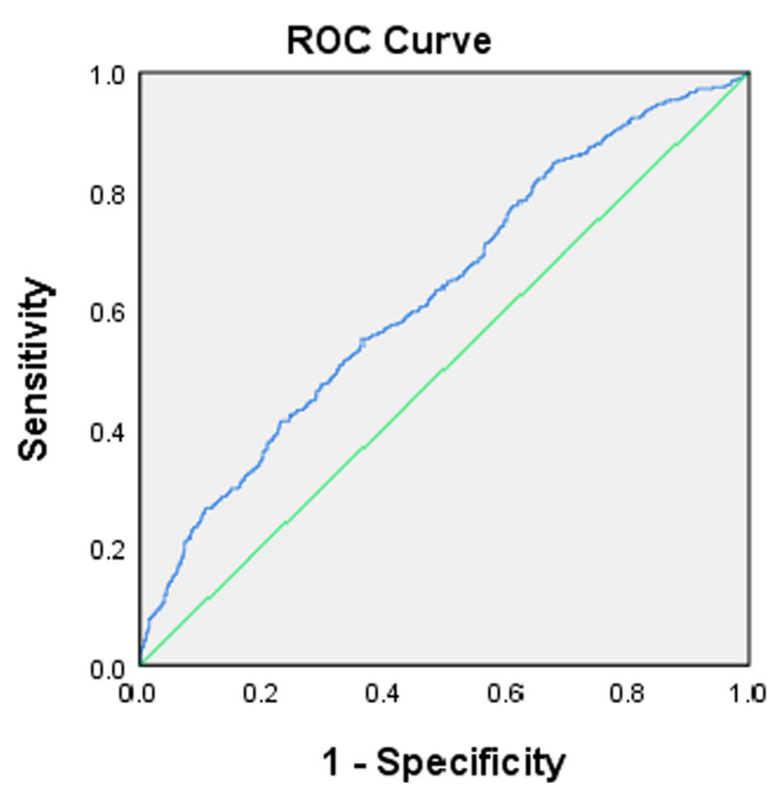

Fig. 7 ROC analysis of the combination of PI, TI, PI/TI, $2 \mathrm{hPI}, 2 \mathrm{hTI}$, and $2 \mathrm{hPI} / 2 \mathrm{hTI}$ for diagnosing prediabetes

Moreover, PI, TI, PI/TI, and 2hTI could significantly enhance the risk of prediabetes. Interestingly, we observed that the combination of 


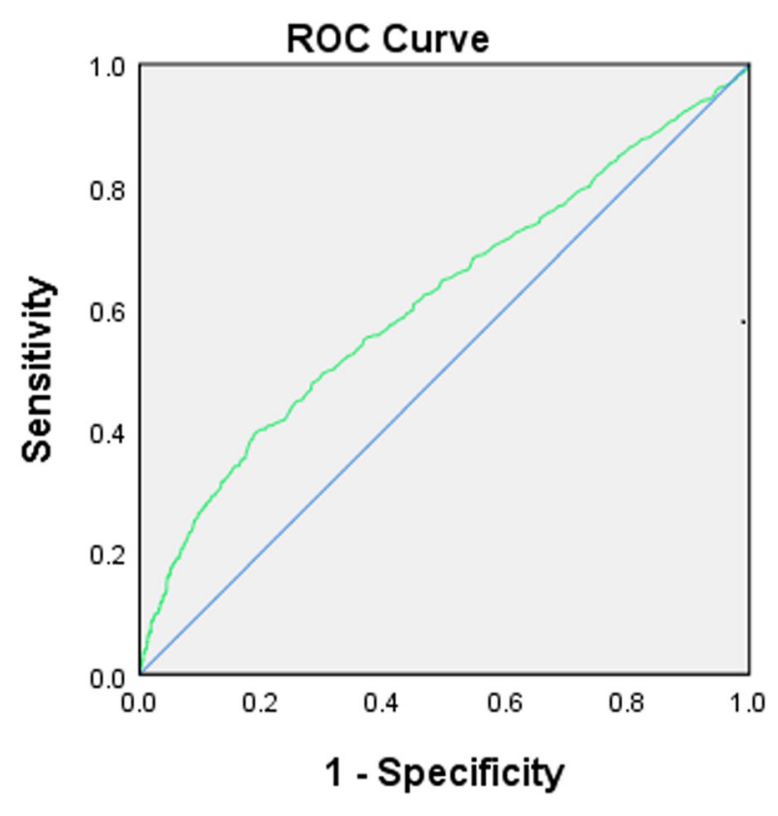

Fig. 8 ROC analysis of HOMA-IR for diagnosing prediabetes

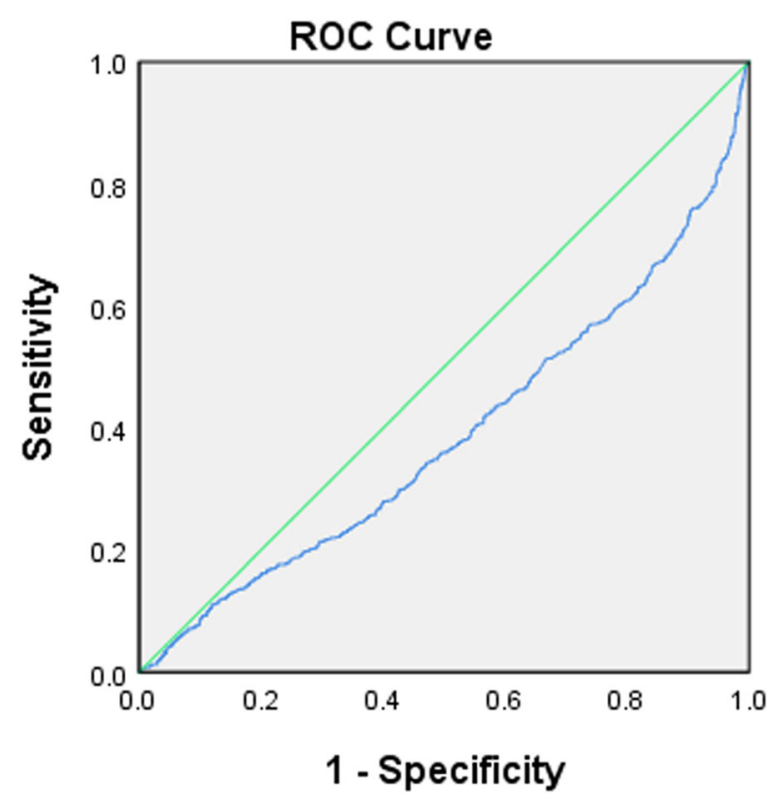

Fig. 9 ROC analysis of HOMA- $\beta$ for diagnosing prediabetes
PI, TI, PI/TI, 2hPI, 2hTI, and 2hPI/2hTI had a higher diagnostic value in diagnosing prediabetes was larger than HOMA-IR- and HOMA- $\beta$ based diagnoses. It suggested that PI, TI, PI/TI, and 2 hTI might be available risk factors for prediabetes.

Prediabetes, typically defined as blood glucose levels above normal but below diabetes thresholds, is an impaired glucose regulation state which is mainly caused by pancreatic $\beta$ cell dysfunction with insulin secretion and hepatic insulin resistance-induced cell damage [21]. Prediabetes is a risk state that defines a high chance of developing diabetes [7]. Insulin is secreted by islet $\beta$ cells as a regulator of blood glucose, which promotes glucose uptake via activation of a series of signaling cascades [22]. Previous research emphasized that PI, TI, and PI/TI were significantly correlated with the risk of diabetes [13, 23-25]. However, it was unclear whether these indicators could influence the risk of prediabetes. In our study, we performed Spearman's correlation analysis and logistic regression analysis to evaluate the impact of PI, TI, PI/TI, 2hPI, 2hTI, and 2hPI/2hTI on the risk of prediabetes in the Hainan Han population. We found that PI was positively correlated with FPG, 2hPG, HbA1c, LDL-C, TG, TC, BMI, WC, and VD3 and negatively related to HDL-C. TI was positively associated with FPG, 2hPG, HbA1c, LDL-C, TG, TC, BMI, and WC, and negatively related to HDL-C and VD3. PI/TI positively correlated with FPG, HDL-C, and VD3, and negatively associated with LDL-C and BMI. Kim's study showed that PI was positively correlated with $2 \mathrm{hPG}$ and TC, and TI was positively related to BMI in T2DM among a Korean population, which is consistent with our findings [26]. We also found that PI/TI positively correlated with FPG, HDL-C, and VD3, and negatively associated with LDL-C and BMI. However, there is no significant association between PI/TI, 2hPG, and TC compared to Kim's results, and these diverse results may be due to the regional difference among them. Besides, 2hPI was positively related to FPG, 2hPG, LDL-C, TG, TC, BMI, WC, and VD3, and negatively related to HbA1c and HDL-C. Moreover, logistic regression analysis indicated that PI, TI, PI/TI, and 2hTI could significantly 
Table 4 Effects of indicators on prediabetes diagnosis

\begin{tabular}{|c|c|c|c|c|c|c|c|}
\hline Variables & AUC & $p$ & $95 \% \mathrm{CI}$ & $\begin{array}{l}\text { Youden } \\
\text { index }\end{array}$ & $\begin{array}{l}\text { Specificity } \\
(\%)\end{array}$ & $\begin{array}{l}\text { Sensitivity } \\
\text { (\%) }\end{array}$ & $\begin{array}{l}\text { Cutoff } \\
\text { value }\end{array}$ \\
\hline $\mathrm{PI}(\mathrm{mmol} / \mathrm{L})$ & 0.543 & 0.002 & $0.515-0.572$ & 0.129 & 76.4 & 36.5 & 15.5 \\
\hline TI $(\mathrm{mmol} / \mathrm{L})$ & 0.554 & $<0.001$ & $0.526-0.583$ & 0.110 & 76.0 & 35.0 & 75.5 \\
\hline $\mathrm{PI} / \mathrm{TI}$ & 0.515 & 0.281 & $0.487-0.543$ & 0.031 & 94.8 & 8.30 & 0.5 \\
\hline 2hPI (mmol/L) & 0.463 & 0.011 & $0.435-0.492$ & 0.012 & 74.0 & 27.2 & 80.5 \\
\hline $2 \mathrm{hTI}(\mathrm{mmol} / \mathrm{L})$ & 0.533 & 0.023 & $0.504-0.561$ & 0.088 & 82.3 & 26.5 & 685.5 \\
\hline $2 \mathrm{hPI} / 2 \mathrm{hTI}$ & 0.497 & 0.848 & $0.469-0.525$ & 0.002 & 99.8 & 0.40 & 0.5 \\
\hline $\begin{array}{l}\mathrm{PI}+\mathrm{TI}+\mathrm{PI} / \\
\mathrm{TI}+2 \mathrm{hPI}+2 \mathrm{hTI}+2 \mathrm{hPI} / \\
2 \mathrm{hTI}\end{array}$ & 0.627 & $<0.0001$ & $0.600-0.654$ & 0.185 & 55.1 & 63.4 & - \\
\hline HOMA-IR & 0.614 & $<0.0001$ & $0.587-0.642$ & 0.206 & 39.8 & 80.7 & 1.875 \\
\hline HOMA- $\beta$ & 0.387 & $<0.0001$ & $0.359-0.415$ & 0.003 & 0.4 & 99.9 & - \\
\hline
\end{tabular}

The cutoff value, AUC, sensitivity, specificity, and Youden index were calculated by ROC analysis. Numbers in bold are statistically significant $(p<0.05)$

$A U C$ area under curve

increase the risk of prediabetes. This finding is consistent with that of Pradhan who reported that PI, TI, and PI/TI are associated with an increased risk of developing T2DM in apparently healthy middle-aged women [13]. In general, it suggest that PI, TI, and PI/TI are candidate risk factors for prediabetes.

We finally investigated the prognostic accuracy of PI, TI, PI/TI, $2 \mathrm{hPI}, 2 \mathrm{hTI}$, and $2 \mathrm{hPI} / 2 \mathrm{hTI}$ for diagnosing prediabetes. The results showed that PI, TI, PI/TI, 2hPI, 2hTI, and 2hPI/2hTI were separately poor at diagnosing subjects with prediabetes; however, the combination of PI, TI, PI/TI, 2hPI, 2hTI, and 2hPI/2hTI had a higher AUC in diagnosing prediabetes than the diagnostic value of HOMA-IR and HOMA- $\beta$. It suggests that the combination of these indicators has a potential role in diagnosing prediabetes; however, larger samples and further studies are required to certify our results. The present study provides the first evidence for the effects of PI, TI, PI/TI, and $2 \mathrm{hTI}$ on the risk of prediabetes in the Chinese Han population.

Our study had several limitations. First, the present study was monocentric in design; a longitudinal study is required to confirm the results. Second, other possible risk factors for prediabetes such as frequent genitourinary infections, rapid changes in vision, history of steroid use, fetal macrosomia in women, obesity, and sedentary lifestyle were not considered in our study because of the very limited information obtained from participants, and we would consider them in future work. Despite these shortcomings, our study gives available evidence for the new risk factors in prediabetes.

\section{CONCLUSION}

Our study showed that PI, TI, PI/TI, and 2hTI could significantly enhance the risk of prediabetes in the Chinese Han population, which gives some useful information for the prevention and management of diabetes in the Chinese population or others.

\section{ACKNOWLEDGEMENTS}

We sincerely thank all participants in this study. 
Funding. This study was supported by the National Key Research and Development Program of China (2016YFC1305000, 2016YFC1305001, and 2018YFC1315603), the National Natural Science Foundation of China (81820108007), and Hainan Provincial Key Research and Development Project (ZDYF2018130). The Rapid Service Fee was funded by the authors.

Authorship. All named authors meet the International Committee of Medical Journal Editors (ICMJE) criteria for authorship for this article, take responsibility for the integrity of the work as a whole, and have given their approval for this version to be published.

Authors' Contributions. Conceptualization: Huibiao Quan; Methodology: Tuanyu Fang, Leweihua Lin, and Lu Lin; Formal analysis and investigation: Qianying Ou, Huachuan Zhang, and Kaining Chen; Writing-original draft preparation: Huibiao Quan; Writing-review and editing: Zhiguang Zhou; Supervision: Zhiguang Zhou.

Disclosures. Huibiao Quan, Tuanyu Fang, Leweihua Lin, Lu Lin, Qianying Ou, Huachuan Zhang, Kaining Chen, and Zhiguang Zhou declare that they have nothing to disclosure.

Compliance with Ethics Guidelines. Our study was approved by the ethics committee of Hainan Affiliated Hospital of Hainan Medical University. All procedures performed in studies involving human participants were in accordance with the Helsinki Declaration of 1964, and its later amendments. All subjects provided informed consent to participate in the study.

Data Availability. The datasets generated during and/or analyzed during the current study are available from the corresponding author on reasonable request.

Open Access. This article is licensed under a Creative Commons Attribution-NonCommercial 4.0 International License, which permits any non-commercial use, sharing, adaptation, distribution and reproduction in any medium or format, as long as you give appropriate credit to the original author(s) and the source, provide a link to the Creative Commons licence, and indicate if changes were made. The images or other third party material in this article are included in the article's Creative Commons licence, unless indicated otherwise in a credit line to the material. If material is not included in the article's Creative Commons licence and your intended use is not permitted by statutory regulation or exceeds the permitted use, you will need to obtain permission directly from the copyright holder. To view a copy of this licence, visit http://creativecommons.org/licenses/by$\mathrm{nc} / 4.0 /$.

\section{REFERENCES}

1. Ferrannini E, Gastaldelli A, Iozzo P. Pathophysiology of prediabetes. Med Clin N Am. 2011;95(2): 327-39. https://doi.org/10.1016/j.mcna.2010.11. 005 (vii-viii).

2. Fonseca VA. Defining and characterizing the progression of type 2 diabetes. Diabetes Care. 2009;32(Suppl 2):S151-6. https://doi.org/10.2337/ dc09-S301.

3. Brannick B, Dagogo-Jack S. Prediabetes and cardiovascular disease: pathophysiology and interventions for prevention and risk reduction. Endocrinol Metab Clin N Am. 2018;47(1):33-50. https://doi. org/10.1016/j.ecl.2017.10.001.

4. Danaei G, Finucane MM, Lu Y, et al. National, regional, and global trends in fasting plasma glucose and diabetes prevalence since 1980: systematic analysis of health examination surveys and epidemiological studies with 370 country-years and 2.7 million participants. Lancet. 2011;378(9785): 31-40. 6736(11)60679-X.

5. Carracher AM, Marathe PH, Close KL. International Diabetes Federation 2017. J Diabetes. 2018;10(5): 353-6. https://doi.org/10.1111/1753-0407.12644.

6. Mainous AG 3rd, Tanner RJ, Baker R, Zayas CE, Harle CA. Prevalence of prediabetes in England from 2003 to 2011: population-based, cross-sectional study. BMJ Open. 2014;4(6): e005002. https://doi.org/10.1136/bmjopen-2014-005002.

7. Tabák AG, Herder C, Rathmann W, Brunner EJ, Kivimäki M. Prediabetes: a high-risk state for 
diabetes development. Lancet. 2012;379(9833): 2279-90. https://doi.org/10.1016/s01406736(12)60283-9.

8. Forbes JM, Cooper ME. Mechanisms of diabetic complications. Physiol Rev. 2013;93(1):137-88. https://doi.org/10.1152/physrev.00045.2011.

9. Echouffo-Tcheugui JB, Narayan KM, Weisman D, Golden SH, Jaar BG. Association between prediabetes and risk of chronic kidney disease: a systematic review and meta-analysis. Diabet Med. 2016;33(12):1615-24. https://doi.org/10.1111/dme. 13113.

10. Lamparter J, Raum P, Pfeiffer N, et al. Prevalence and associations of diabetic retinopathy in a large cohort of prediabetic subjects: the Gutenberg Health Study. J Diabet Complic. 2014;28(4):482-7. https://doi.org/10.1016/j.jdiacomp.2014.02.008.

11. American Diabetes Association. 5. Prevention or delay of type 2 diabetes: standards of medical care in diabetes-2018. Diabetes Care. 2018;41(Suppl 1): S51-s54. https://doi.org/10.2337/dc18-S005.

12. Rydén L, Grant PJ, Anker SD, et al. ESC Guidelines on diabetes, pre-diabetes, and cardiovascular diseases developed in collaboration with the EASD: the Task Force on diabetes, pre-diabetes, and cardiovascular diseases of the European Society of Cardiology (ESC) and developed in collaboration with the European Association for the Study of Diabetes (EASD). Eur Heart J. 2013;34(39):3035-87. https:// doi.org/10.1093/eurheartj/eht108.

13. Pradhan $\mathrm{AD}$, Manson JE, Meigs JB, et al. Insulin, proinsulin, proinsulin: insulin ratio, and the risk of developing type 2 diabetes mellitus in women. Am J Med. 2003;114(6):438-44. https://doi.org/10.1016/ s0002-9343(03)00061-5.

14. Kahn SE, Halban PA. Release of incompletely processed proinsulin is the cause of the disproportionate proinsulinemia of NIDDM. Diabetes. 1997;46(11):1725-32.

15. Pfützner A, Kunt T, Hohberg C, et al. Fasting intact proinsulin is a highly specific predictor of insulin resistance in type 2 diabetes. Diabetes Care. 2004;27(3):682-7.

16. Zethelius B, Byberg L, Hales C, Lithell H, Berne C. Proinsulin and acute insulin response independently predict type 2 diabetes mellitus in menreport from 27 years of follow-up study. Diabetologia. 2003;46(1):20-6.

17. Hanley AJG, D'Agostino Jr R, Wagenknecht LE, et al. Increased proinsulin levels and decreased acute insulin response independently predict the incidence of type 2 diabetes in the insulin resistance atherosclerosis study. Diabetes. 2002;51(4): 1263-70.

18. Mykkänen L, Haffner SM, Hales CN, Rönnemaa T, Laakso M. The relation of proinsulin, insulin, and proinsulin-to-insulin ratio to insulin sensitivity and acute insulin response in normoglycemic subjects. Diabetes. 1997;46(12):1990-5.

19. American Diabetes Association. Classification and diagnosis of diabetes: standards of medical care in diabetes-2018. Diabetes Care. 2018;41(Suppl 1): S13-27. https://doi.org/10.2337/dc18-S002.

20. Matthews DR, Hosker JP, Rudenski AS, Naylor BA, Treacher DF, Turner RC. Homeostasis model assessment: insulin resistance and beta-cell function from fasting plasma glucose and insulin concentrations in man. Diabetologia. 1985;28(7): 412-9. https://doi.org/10.1007/bf00280883.

21. Henquin JC, Dufrane D, Gmyr V, Kerr-Conte J, Nenquin M. Pharmacological approach to understanding the control of insulin secretion in human islets. Diabetes Obes Metab. 2017;19(8):1061-70. https://doi.org/10.1111/dom.12887.

22. Kuai M, Li Y, Sun X, et al. A novel formula SangTong-Jian improves glycometabolism and ameliorates insulin resistance by activating PI3K/AKT pathway in type 2 diabetic KKAy mice. Biomed Pharmacother. 2016;84:1585-94. https://doi.org/ 10.1016/j.biopha.2016.10.101.

23. Ashley KE, Hillegass WB. Insulin-treated diabetes mellitus: an actionable risk factor and marker after percutaneous coronary intervention. Catheter Cardiovasc Interv. 2020;96(2):309-10. https://doi.org/ 10.1002/ccd.29170.

24. Truyen I, De Pauw P, Jørgensen PN, et al. Proinsulin levels and the proinsulin: c-peptide ratio complement autoantibody measurement for predicting type 1 diabetes. Diabetologia. 2005;48(11):2322-9. https://doi.org/10.1007/s00125-005-1959-0.

25. Pfützner A, Manessis A, Hanna MR, Lewin J. Increased intact proinsulin in the oral glucose challenge sample is an early indicator for future type 2 diabetes development - case reports and evidence from the literature. Clin Lab. 2020. https://doi.org/10.7754/Clin.Lab.2019.191011.

26. Kim NH, Kim DL, Choi KM, Baik SH, Choi DS. Serum insulin, proinsulin and proinsulin/insulin ratio in type 2 diabetic patients: as an index of betacell function or insulin resistance. Korean J Intern Med. 2000;15(3):195-201. https://doi.org/10.3904/ kjim.2000.15.3.195. 